\title{
BMJ Open Epidemiology and outcome of adult out-of-hospital cardiac arrest of non-cardiac origin in Osaka: a population-based study
}

Tetsuhisa Kitamura, ${ }^{1}$ Kosuke Kiyohara, ${ }^{2}$ Tomohiko Sakai, ${ }^{3}$ Taku Iwami, ${ }^{4}$ Chika Nishiyama, ${ }^{5}$ Kentaro Kajino, ${ }^{6}$ Tatsuya Nishiuchi, ${ }^{7}$ Yasuyuki Hayashi, ${ }^{8}$ Yusuke Katayama, ${ }^{3}$ Kazuhisa Yoshiya, ${ }^{3}$ Takeshi Shimazu ${ }^{3}$

To cite: Kitamura T, Kiyohara K, Sakai T, et al. Epidemiology and outcome of adult out-of-hospital cardiac arrest of non-cardiac origin in Osaka: a populationbased study. BMJ Open 2014;4:e006462. doi:10.1136/bmjopen-2014006462

- Prepublication history and additional material is available. To view please visit the journal (http://dx.doi.org/ 10.1136/bmjopen-2014006462).

Received 25 August 2014 Revised 3 November 2014 Accepted 10 November 2014

CrossMark

For numbered affiliations see end of article.

Correspondence to Dr Taku Iwami; iwamit@e-mail.jp

\section{ABSTRACT}

Objectives: To evaluate epidemiological characteristics of out-of-hospital cardiac arrests (OHCAs) by detailed non-cardiac cause and factors associated with the outcomes after OHCAs of non-cardiac origin.

Design: A prospective, population-based observational study.

Setting: The Utstein Osaka Project.

Participants: 14164 adult patients aged $\geq 20$ years old with OHCAs due to non-cardiac origin who were resuscitated by emergency-medical-service personnel or bystanders, and then were transported to medical institutions from January 2005 to December 2011.

Primary outcome measures: One-month survival after OHCA. Multiple logistic regression analysis was used to assess factors that were potentially associated with the outcome.

Results: During the study period, the 1-month survival rate was $5.3 \%(755 / 14164)$. The proportion of 1 -month survival was $6.2 \%(510 / 8239)$ in external causes, $6.5 \%$ $(94 / 1148)$ in respiratory diseases, $0.8 \%(11 / 1309)$ in malignant tumours, $4.9 \%$ (55/1114) in strokes and $4.1 \%(85 / 2054)$ in others. As for external causes, the proportion of 1 -month survival was $14.3 \%(382 / 2670)$ in asphyxia, 4.2\% (84/1999) in hanging, 0.7\% (9/1300) in fall, 1.1\% (12/1062) in drowning, 1.6\% (12/765) in traffic injury, $3.7 \%(7 / 187)$ in drug overuse and $1.6 \%$ $(4 / 256)$ in unclassified external causes. In a multivariate analysis, adults aged $<65$ years old with arrests witnessed by bystanders, with normal activities of daily living before the arrests, having ventricular fibrillation arrests, having arrests in public places, intravenous fluid levels and early Emergency Medical Service response time were significant predictors for 1-month outcome after OHCAs of non-cardiac origin. The proportion of 1-month survival of all OHCAs of non-cardiac origin did not significantly increase (from $4.3 \%(86 / 2023)$ in 2005 to $4.9 \%$ (105/2126) in 2011) and the adjusted OR for one-increment of year was $1.01(95 \% \mathrm{Cl} 0.97$ to 1.06).

Conclusions: From a large OHCA registry in Osaka, we demonstrated that 1-month survival after OHCAs of non-cardiac origin was poor and stable.

\section{Strengths and limitations of this study}

- This study showed that 1-month survival after out-of-hospital cardiac arrestss of non-cardiac origin was poor and the survival trends did not improve year-by-year in Osaka during the study period from 2005 to 2011. In addition, survival exceedingly differed in detailed non-cardiac origin.

- The category of presumed non-cardiac causes is made clinically, as per the Utstein-style international guidelines for cardiac arrest data reporting.

- Information on postarrest cares that might affect survival after OHCA is lacking.

\section{INTRODUCTION}

Out-of-hospital cardiac arrest (OHCA) is a leading cause of death in the industrialised world. ${ }^{1-4}$ Although improvements in the chain of survival including the development of a public-access defibrillation system and revisions to cardiopulmonary resuscitation (CPR) guidelines have led to increased survival after OHCA of cardiac origin in some communities, ${ }^{5-7}$ the outcome after OHCAs of noncardiac origin remains generally poor. ${ }^{7-13}$

Importantly, 20-40\% of adult OHCAs were reportedly of non-cardiac origin. ${ }^{7-13}$ However, epidemiological characteristics of OHCA of non-cardiac origin have not been sufficiently investigated as much as those of OHCA of cardiac origin. Therefore, the evaluation of characteristics, trends and outcomes by detailed non-cardiac cause and understanding the factors associated with the outcomes are needed to improve the survival after OHCAs of non-cardiac origin.

The Utstein Osaka Project is a large prospective population-based cohort study of OHCA in Osaka, Japan, covering about 8.8 million residents. ${ }^{5}$ During the 7 years from 2005 to 2011, we enrolled approximately 
14000 cases of OHCAs of non-cardiac origin before Emergency Medical Service (EMS) arrival. The present study aimed to evaluate the epidemiological characteristics of OHCAs by detailed non-cardiac cause. In addition, we evaluated factors associated with the outcomes after OHCAs of non-cardiac origin in a multivariate analysis.

\section{METHODS}

\section{Study design and setting}

The Utstein Osaka Project is a prospective, populationbased registry of OHCA that is based on the standardised Utstein style. ${ }^{14}{ }^{15}$ This study enrolled adult patients aged $\geq 20$ years suffering OHCAs of non-cardiac origin before EMS arrival, who were resuscitated by EMS personnel or bystanders, and were transported to medical institutions in Osaka Prefecture from 1 January 2005 to 31 December 2011. In this study, we excluded paediatric patients with OHCA because characteristics and outcomes from OHCAs differed between children and adults. ${ }^{16} 17$

Cardiac arrest was defined as the cessation of cardiac mechanical activity as confirmed by the absence of signs of circulation. ${ }^{14} 15$ In this study, the arrests were classified into those of presumed cardiac origin and non-cardiac origin, the latter resulting from external causes, respiratory diseases, malignant tumours, strokes and any other noncardiac causes based on hospital medical records. Furthermore, external causes were divided into seven categories: asphyxia, hanging, fall, drowning, traffic injury, drug overuse and unclassified external causes. These diagnoses were made clinically by the physician in charge, working in collaboration with the EMS personnel.

\section{EMS organisation in Osaka}

Details of the EMS system in Osaka were described previously. ${ }^{5}$ Osaka is the second largest prefecture in Japan with a population of approximately 8.8 million inhabitants in an area of $1892 \mathrm{~km}^{2}$. In Osaka, there are 34 fire stations with emergency dispatch centres. The EMS system is operated by the local fire stations. When called, an ambulance is dispatched from the nearest fire station. Emergency services are provided $24 \mathrm{~h}$ each day by them, which are single-tiered in 32 stations and twotiered in 2 stations. The latter use medics followed by physicians.

Most highly trained prehospital emergency care providers are called emergency life-saving technicians (ELSTs). Usually, each ambulance has a crew of three emergency providers including at least one ELST. They are allowed to insert an intravenous line and an adjunct airway, and to use a semiautomated external defibrillator for patients with OHCA. Specially trained ELSTs have been permitted to perform tracheal intubation since July 2004 and to administer intravenous epinephrine since April 2006.

Do-not-resuscitate orders or living wills are not generally accepted in Japan. EMS providers are not permitted to terminate resuscitation in the field. Therefore, almost all patients with OHCA who were treated by EMS personnel were transported to a hospital and enrolled in the Utstein Osaka Project, excluding those with decapitation, incineration, decomposition, rigor mortis or dependent cyanosis.

\section{CPR and AED training for the general public}

The use of an automated external defibrillator (AED) by citizens has been legally permitted since July 2004. In Osaka, approximately 14000 citizens per year participated in the CPR training programmes, consisting of conventional CPR including chest compressions, mouth-to-mouth ventilation and AED usage by local fire departments, the Japan Red Cross, Inc and the Osaka Life Support Association. ${ }^{5}$ All EMS providers perform CPR according to Japanese CPR guidelines. ${ }^{4}$

\section{Data collection and quality control}

Data collection was prospectively conducted using a form that included data recommended in the Utstein-style reporting guidelines for cardiac arrests. ${ }^{14}{ }^{15}$ These data included gender, age, first documented cardiac rhythm, witness status, location of arrests, activity of daily living (ADL) before arrests, time courses of resuscitation, type of bystander-initiated CPR, public-access AED use, intravascular fluid, tracheal intubation and administration of intravascular epinephrine as well as prehospital return of spontaneous circulation (ROSC), total ROSC, 1-month survival and neurological status 1 month after the event. First documented rhythm was recorded and diagnosed by the EMS personnel with semiautomated defibrillators on the scene, and confirmed by the physician who was responsible for the online medical direction. Bystander CPR included chest compression-only CPR and conventional CPR with rescue breathing. A series of EMS times of call receipt, vehicle arrival at the scene, contact with patients, initiation of CPR, defibrillation by EMS and hospital arrival were recorded automatically at the dispatch centre.

The data form was completed by the EMS personnel in cooperation with the physicians in charge of the patients, and the data were integrated into the registry system on the Information Center for Emergency Medical Services of Osaka, and then checked by the investigators. If the data sheet was incomplete, the relevant EMS personnel were contacted and questioned for data completion.

All survivors suffering OHCA were followed up for up to 1 month after the event by the EMS personnel in charge. One month neurological outcomes were determined by the physician responsible for treating the patient, using the cerebral performance category (CPC) scale: category 1, good cerebral performance; category 2 , moderate cerebral disability; category 3 , severe cerebral disability; category 4, coma or vegetative state; and category 5 , death. ${ }^{14} 15$ 


\section{Outcome measures}

The main outcome measure was 1-month survival. Secondary outcome measures included prehospital and total ROSCs, admission to hospital and 1-month survival with neurologically favourable outcome. Neurologically favourable outcome was defined as CPC category 1 or $2 .^{14} 15$

\section{Statistical analysis}

In this study, patient and EMS characteristics of OHCAs of non-cardiac origin and their outcomes were compared between the groups using unpaired analysis of variance for numerical variables and $\chi^{2}$ test or Fisher's exact test for categorical variables by cause of arrest. First, noncardiac causes were divided into the following five groups: external causes, respiratory diseases, malignant tumours, strokes and any other non-cardiac causes. Next, external causes were further divided into asphyxia, hanging, fall, drowning, traffic injury, drug overuse and unclassified external causes. Age-adjusted annual incidence of OHCAs by non-cardiac origin was calculated by the direct method using 2005 census data and 1985 Japanese model population. ${ }^{18}{ }^{19}$ Poisson regression models for the trends in the incidence and 1-month survival rate were used. Multiple logistic regression analysis assessed the factors associated with 1-month survival and neurological favourable outcome, and adjusted ORs (AORs) and their 95\% CIs were calculated. As potential confounders, factors that were biologically essential and considered to be associated with clinical outcomes were taken in the multivariable analyses. ${ }^{7}$ These variables included age (20-64, $\geq 65$ years old), gender (men, women), witness status (none, witnessed by bystanders), ADL before arrests (good, other), first documented rhythm (ventricular fibrillation (VF), non-VF), bystander CPR status (none, compression-only CPR, conventional CPR), type of non-cardiac causes (the 11 categories described above), location of arrests (homes, public places, work places, healthcare facilities, others), intravascular fluid (yes, no), intubation (yes, no), epinephrine (yes, no), EMS response time (call to contact with patients) and year of arrest. In addition, we conducted a multivariate analysis of 1-month survival from OHCAs of non-cardiac origin after dividing the two groups: internal (respiratory diseases, malignant tumours and strokes) and external (asphyxia, hanging, fall, drowning, traffic injury and drug overuse) causes.

All statistical analyses were performed using the SPSS statistical package V.21.0J (IBM Corp, Armonk, New York, USA). All of the tests were two-tailed and $p$ values of $<0.05$ were considered statistically significant.

\section{RESULTS}

Figure 1 shows an overview of the study patients based on the Utstein template. A total of 47735 adult arrests were documented during these 7 years. Resuscitation was attempted in 43845 , and 15505 of these were of non-cardiac origin. Excluding 1341 victims who were witnessed by EMS (arrests after EMS arrival), 14164 (5561 in bystander-witnessed cases and 8603 in non-witnessed

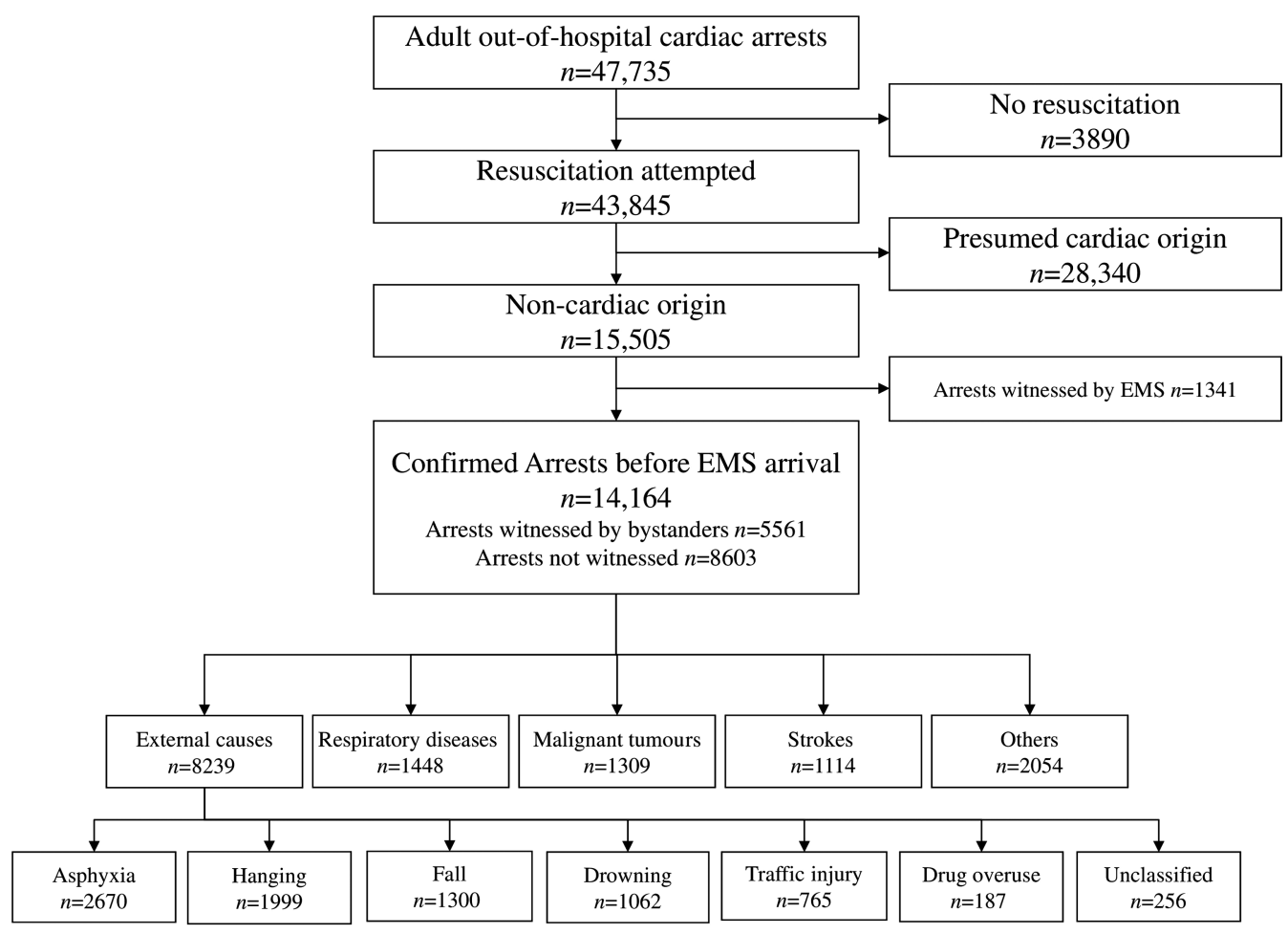

Figure 1 Overview of EMS-treated cardiac arrests with an abridged Utstein template from 1 January 2005 to 31 December 2011. EMS, emergency medical service. 
Table 1 Age-adjusted incidences and unadjusted 1-month survival rate of out-of-hospital cardiac arrests of non-cardiac origin according to the cause over time

\begin{tabular}{|c|c|c|c|c|c|c|c|c|}
\hline & 2005 & 2006 & 2007 & 2008 & 2009 & 2010 & 2011 & $p$ for trend \\
\hline \multicolumn{9}{|c|}{ Age-adjusted incidence per 100000 persons } \\
\hline External causes & 12.4 & 12.3 & 13.2 & 12.8 & 13.2 & 13.3 & 13.3 & 0.024 \\
\hline Asphyxia & 2.7 & 3.0 & 2.8 & 3.4 & 3.1 & 2.9 & 2.9 & 0.726 \\
\hline Hanging & 3.4 & 3.4 & 4.1 & 3.4 & 3.7 & 3.9 & 3.9 & 0.158 \\
\hline Fall & 2.4 & 2.5 & 3.1 & 2.4 & 2.9 & 3.0 & 2.7 & 0.396 \\
\hline Drowning & 1.2 & 1.1 & 1.2 & 1.4 & 1.2 & 1.3 & 1.6 & 0.065 \\
\hline Traffic injury & 1.6 & 1.5 & 1.4 & 1.4 & 1.4 & 1.5 & 1.4 & 0.229 \\
\hline Drug overdose & 0.5 & 0.4 & 0.2 & 0.4 & 0.4 & 0.4 & 0.3 & 0.304 \\
\hline Unclassified & 0.5 & 0.5 & 0.4 & 0.3 & 0.5 & 0.4 & 0.5 & 0.447 \\
\hline Respiratory diseases & 2.2 & 1.8 & 1.8 & 1.7 & 1.3 & 1.3 & 1.6 & 0.018 \\
\hline Malignant tumours & 1.6 & 1.8 & 1.8 & 1.7 & 1.5 & 1.3 & 1.6 & 0.109 \\
\hline Strokes & 2.0 & 1.8 & 1.8 & 1.6 & 1.4 & 1.2 & 1.3 & $<0.001$ \\
\hline Others & 2.7 & 3.3 & 3.1 & 2.9 & 2.7 & 2.5 & 2.4 & 0.087 \\
\hline \multicolumn{9}{|c|}{ Unadjusted 1-month survival, \% (n/N) } \\
\hline External causes & $4.8(53 / 1100)$ & $6.8(72 / 1059)$ & $5.7(66 / 1164)$ & $7.2(85 / 1184)$ & $7.1(86 / 1207)$ & $6.1(75 / 1225)$ & $5.6(73 / 1300)$ & 0.736 \\
\hline Asphyxia & $10.4(35 / 337)$ & $15.4(53 / 344)$ & $13.0(44 / 338)$ & $15.6(67 / 430)$ & $16.3(66 / 406)$ & $14.8(58 / 393)$ & $14.0(59 / 422)$ & 0.374 \\
\hline Hanging & $4.6(12 / 261)$ & $4.7(12 / 255)$ & $5(16 / 318)$ & $4.8(13 / 273)$ & $4.9(14 / 287)$ & $3.3(10 / 301)$ & $2.3(7 / 304)$ & 0.101 \\
\hline Fall & $0.6(1 / 159)$ & $0.6(1 / 169)$ & $0.9(2 / 219)$ & $1.2(2 / 165)$ & $0.0(0 / 197)$ & $0.5(1 / 208)$ & $1.1(2 / 183)$ & NA \\
\hline Drowning & $1.3(2 / 151)$ & $3.3(4 / 120)$ & $0.0(0 / 128)$ & $1.3(2 / 159)$ & $2.1(3 / 144)$ & $0.7(1 / 148)$ & $0.0(0 / 212)$ & NA \\
\hline Traffic injury & $0.9(1 / 116)$ & $1.0(1 / 101)$ & $1.8(2 / 109)$ & $0.9(1 / 106)$ & $1.9(2 / 103)$ & $1.7(2 / 115)$ & $2.6(3 / 115)$ & 0.027 \\
\hline Drug overdose & $3.0(1 / 33)$ & $0.0(0 / 29)$ & $5.6(1 / 18)$ & $0.0(0 / 25)$ & $3.3(1 / 30)$ & $11.1(3 / 27)$ & $4.0(1 / 25)$ & NA \\
\hline Unclassified & $2.3(1 / 43)$ & $2.4(1 / 41)$ & $2.9(1 / 34)$ & $0.0(0 / 26)$ & $0.0(0 / 40)$ & $0.0(0 / 33)$ & $2.6(1 / 39)$ & NA \\
\hline Respiratory diseases & $6.4(17 / 267)$ & $3.9(8 / 206)$ & $8.0(17 / 212)$ & $9.8(21 / 214)$ & $6.7(11 / 165)$ & 4.7 (8/169) & $5.6(12 / 215)$ & 0.875 \\
\hline Malignant tumors & $0.5(1 / 186)$ & $0.5(1 / 194)$ & $1.0(2 / 202)$ & $1.0(2 / 196)$ & $0.0(0 / 178)$ & $2.5(4 / 159)$ & $0.5(1 / 194)$ & NA \\
\hline Strokes & $3.6(7 / 196)$ & $6.1(11 / 179)$ & $4.5(8 / 176)$ & $3.2(5 / 154)$ & $4.9(7 / 143)$ & $6.0(8 / 134)$ & $6.8(9 / 132)$ & 0.241 \\
\hline Others & $2.9(8 / 277)$ & $7.0(22 / 314)$ & $1.3(4 / 308)$ & $4.5(14 / 311)$ & $4.3(12 / 278)$ & $5.3(15 / 281)$ & $3.5(10 / 285)$ & 0.808 \\
\hline
\end{tabular}


Table 2 Patient and EMS characteristics of out-of-hospital cardiac arrests of non-cardiac origin according to the cause

\begin{tabular}{|c|c|c|c|c|c|c|c|c|c|c|c|c|c|}
\hline \multirow[b]{2}{*}{ Age, year, mean (SD) } & \multicolumn{2}{|c|}{$\begin{array}{l}\text { Total } \\
(n=14164)\end{array}$} & \multicolumn{2}{|c|}{$\begin{array}{l}\text { External } \\
\text { causes } \\
(n=8239)\end{array}$} & \multicolumn{2}{|c|}{$\begin{array}{l}\text { Respiratory } \\
\text { diseases } \\
(n=1448)\end{array}$} & \multicolumn{2}{|c|}{$\begin{array}{l}\text { Malignant } \\
\text { tumors } \\
(n=1309)\end{array}$} & \multicolumn{2}{|c|}{$\begin{array}{l}\text { Strokes } \\
(n=1114)\end{array}$} & \multicolumn{2}{|c|}{$\begin{array}{l}\text { Others } \\
(n=2054)\end{array}$} & \multirow{2}{*}{$\begin{array}{l}\text { p Value } \\
<0.001\end{array}$} \\
\hline & 66.8 & $(19.0)$ & 63.5 & $(20.5)$ & 76.1 & $(14.2)$ & 71.9 & $(12.0)$ & 67.7 & $(14.7)$ & 69.8 & $(17.6)$ & \\
\hline Age group, $\mathrm{n}(\%)$ & & & & & & & & & & & & & $<0.001$ \\
\hline Adults aged $20-64$ years & 5513 & (38.9) & 3826 & $(46.4)$ & 229 & $(15.8)$ & 345 & $(26.4)$ & 447 & $(40.1)$ & 666 & $(32.4)$ & \\
\hline Elderly aged $\geq 65$ years & 8651 & (61.1) & 4413 & $(53.6)$ & 1219 & (84.2) & 964 & (73.6) & 667 & (59.9) & 1388 & $(67.6)$ & \\
\hline Men, n (\%) & 8215 & $(58.0)$ & 4789 & $(58.1)$ & 844 & (58.3) & 881 & (67.3) & 559 & (50.2) & 1142 & $(55.6)$ & $<0.001$ \\
\hline Arrests witnessed by bystanders, $\mathrm{n}(\%)$ & 5561 & (39.3) & 2952 & (35.8) & 682 & $(47.1)$ & 639 & $(48.8)$ & 493 & (44.3) & 795 & (38.7) & $<0.001$ \\
\hline Normal activities of daily living, $n(\%)$ & 8522 & $(60.2)$ & 5213 & (63.3) & 653 & $(45.1)$ & 443 & (33.8) & 896 & $(80.4)$ & 1317 & $(64.1)$ & $<0.001$ \\
\hline First documented rhythm, n (\%) & & & & & & & & & & & & & $<0.001$ \\
\hline VF & 324 & (2.3) & 119 & $(1.4)$ & 35 & $(2.4)$ & 26 & $(2.0)$ & 69 & $(6.2)$ & 75 & (3.7) & \\
\hline PEA & 3356 & (23.7) & 1853 & (22.5) & 394 & $(27.2)$ & 262 & $(20.0)$ & 329 & $(29.5)$ & 518 & $(25.2)$ & \\
\hline Asystole & 10196 & (72.0) & 6124 & (74.3) & 983 & (67.9) & 1008 & (77.0) & 647 & (58.1) & 1434 & (69.8) & \\
\hline Others & 288 & (2.0) & 143 & $(1.7)$ & 36 & (2.5) & 13 & $(1.0)$ & 69 & (6.2) & 27 & (1.3) & \\
\hline Location of arrest, n (\%) & & & & & & & & & & & & & $<0.001$ \\
\hline Homes & 9010 & $(63.6)$ & 4435 & $(53.8)$ & 1098 & $(75.8)$ & 1217 & (93.0) & 801 & (71.9) & 1459 & $(71.0)$ & \\
\hline Public places & 2035 & (14.4) & 1608 & (19.5) & 59 & $(4.1)$ & 24 & $(1.8)$ & 156 & (14.0) & 188 & $(9.2)$ & \\
\hline Work places & 346 & $(2.4)$ & 223 & $(2.7)$ & 7 & $(0.5)$ & 4 & $(0.3)$ & 48 & $(4.3)$ & 64 & (3.1) & \\
\hline Healthcare facilities & 1505 & $(10.6)$ & 904 & $(11.0)$ & 248 & $(17.1)$ & 55 & $(4.2)$ & 63 & $(5.7)$ & 235 & $(11.4)$ & \\
\hline Others & 1268 & $(9.0)$ & 1069 & (13.0) & 36 & $(2.5)$ & 9 & $(0.7)$ & 46 & $(4.1)$ & 108 & $(5.3)$ & \\
\hline Public-access AED use, $n$ (\%) & 13 & $(0.1)$ & 4 & $(0.05)$ & 2 & $(0.1)$ & 0 & $(0.0)$ & 5 & $(0.4)$ & 2 & $(0.1)$ & 0.001 \\
\hline Type of bystander CPR, n (\%) & & & & & & & & & & & & & $<0.001$ \\
\hline No CPR & 9023 & (63.7) & 5383 & (65.3) & 836 & $(57.7)$ & 889 & (67.9) & 633 & $(56.8)$ & 1282 & $(62.4)$ & \\
\hline Chest compression-only CPR & 3288 & (23.2) & 1811 & (22.0) & 408 & (28.2) & 297 & (22.7) & 283 & $(25.4)$ & 489 & (23.8) & \\
\hline Conventional CPR with rescue breathing & 1853 & (13.1) & 1045 & (12.7) & 204 & $(14.1)$ & 123 & $(9.4)$ & 198 & $(17.8)$ & 283 & $(13.8)$ & \\
\hline Intravascular fluid, $\mathrm{n}(\%)$ & 2320 & (16.4) & 1458 & (17.7) & 202 & $(14.0)$ & 113 & (8.6) & 230 & (20.6) & 317 & (15.4) & $<0.001$ \\
\hline Intubation, $\mathrm{n}(\%)$ & 2639 & (18.6) & 1364 & (16.6) & 338 & (23.3) & 242 & $(18.5)$ & 257 & $(23.1)$ & 438 & (21.3) & $<0.001$ \\
\hline Epinephrine, $\mathrm{n}(\%)$ & 987 & $(7.0)$ & 572 & $(6.9)$ & 88 & $(6.1)$ & 49 & (3.7) & 125 & (11.2) & 153 & $(7.4)$ & $<0.001$ \\
\hline $\begin{array}{l}\text { Call to contact with a patient by EMS } \\
\text { (EMS response time), min, mean (SD) }\end{array}$ & 7.9 & $(4.1)$ & 8.0 & $(4.6)$ & 7.7 & $(3.0)$ & 7.7 & $(2.7)$ & 7.7 & $(2.8)$ & 7.9 & (3.8) & 0.003 \\
\hline Call to CPR by EMS, min, mean (SD) & 8.5 & $(4.5)$ & 8.8 & $(5.1)$ & 8.1 & $(3.1)$ & 8.1 & $(2.8)$ & 8.2 & $(2.9)$ & 8.4 & $(4.2)$ & $<0.001$ \\
\hline Call to hospital arrival, min, mean (SD) & 28.2 & (8.6) & 28.4 & (8.6) & 27.3 & $(8.2)$ & 28.0 & (8.9) & 28.2 & $(8.4)$ & 28.1 & (8.7) & 0.001 \\
\hline
\end{tabular}


cases) were eligible for our analyses. Among these arrests, $8239(58.2 \%)$ were due to external causes, 1448 $(10.2 \%)$ respiratory diseases, 1309 (9.2\%) malignant tumours, $1114(7.9 \%)$ strokes and $2054(14.5 \%)$ were due to others. Among external causes, 2670 (16.5\%) were from asphyxia, 1999 (14.1\%) hanging, 1300 (9.2\%) fall, $1062(7.5 \%)$ drowning, $765(5.4 \%)$ traffic injury and $256(1.8 \%)$ were from unclassified external cause. We could not obtain information on 1-month survival and neurological status for $7(0.05 \%)$ among the 14164 eligible victims.

The age-adjusted annual incidence rates per 100000 persons by non-cardiac cause were calculated over time (table 1). The incidence rate of OHCAs from external causes significantly increased from 12.4 in 2005 to 13.3 in 2011 ( $\mathrm{p}$ for trend=0.024). The incidence rate significantly decreased among patients with OHCA with respiratory diseases (from 2.2 in 2005 to 1.6 in 2011, p for trend=0.018) and strokes (from 2.0 in 2005 to 1.3 in 2011, p for trend $<0.001$ ). The unadjusted 1-month survival rates by non-cardiac cause were almost stable during the study period.

Patient and EMS characteristics of OHCAs of noncardiac origin according to the cause are shown in table 2 and their outcomes in table 3. The mean age of all patients with OHCA of non-cardiac origin was 66.8 years and males were $58.0 \%$. The proportion of bystanderwitnessed arrests, ADL before arrests, first documented rhythm, type of bystander CPR and advanced life supports such as intravascular fluid, intubation and epinephrine, exceedingly varied between the five groups. In all patients, the rate of 1-month survival and neurologically favourable outcome was $5.3 \%$ and $1.3 \%$. The proportion of 1 -month survival was $6.2 \%$ in external causes, $6.5 \%$ in respiratory diseases, $0.8 \%$ in malignant tumours, $4.9 \%$ in strokes and $4.1 \%$ in others. Furthermore, patient and EMS characteristics of OHCAs from external causes are shown in table 4, and their outcomes in table 5 . The characteristics and outcomes varied between the seven groups. The proportion of 1-month survival was $14.3 \%$ in asphyxia, $4.2 \%$ in hanging, $0.7 \%$ in fall, $1.1 \%$ in drowning, $1.6 \%$ in traffic injury, $3.7 \%$ in drug overuse and $1.6 \%$ in unclassified external cause. The proportion of bystander chest compression-only CPR and conventional CPR with rescue breathing was $23.2 \%$ and $13.1 \%$ in whole OHCAs of noncardiac origin, and $22.1 \%$ and $14.3 \%$ in bystanderwitnessed OHCAs.

Table 6 shows factors contributing to 1-month survival and neurologically favourable outcome after OHCAs with non-cardiac origin. In 1-month survival, adults aged $<65$ years old (AOR $1.36,95 \%$ CI 1.12 to 1.65 ), arrests witnessed by bystanders (AOR 4.13, 95\% CI 3.35 to 5.09), good ADL before arrests (AOR 1.23, 95\% CI 1.03 to 1.47), VF as first documented rhythm (AOR 2.04, 95\% CI 1.42 to 2.92 ), public places (AOR $1.45,95 \%$ CI 1.10 to 1.91), intravenous fluid levels (AOR 1.45, 95\% CI 1.14 to 1.84 ) and early EMS response time (AOR for one-increment of minute $0.92,95 \%$ CI 0.90 to 0.095 )

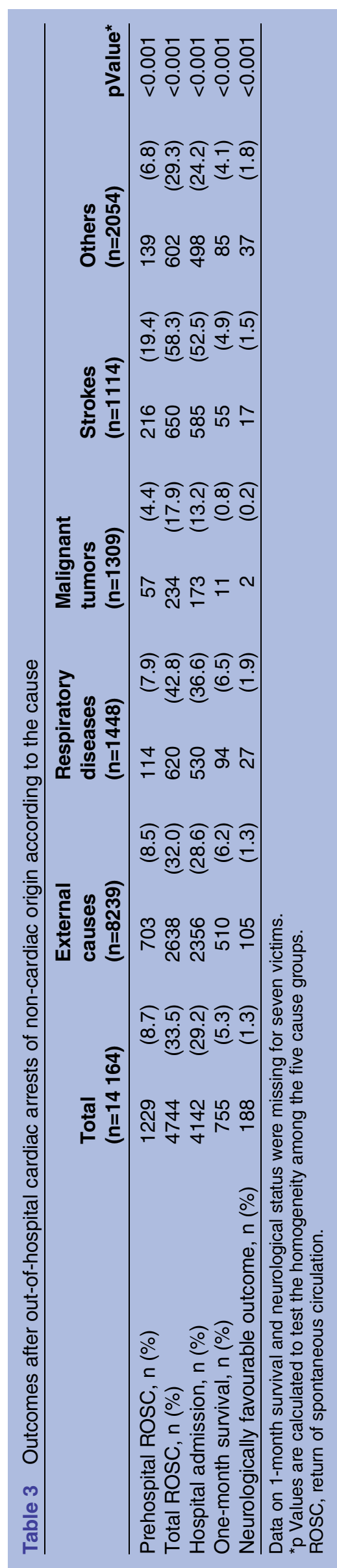


Table 4 Patient and EMS characteristics of out-of-hospital cardiac arrests from external causes according to the cause

\begin{tabular}{|c|c|c|c|c|c|c|c|c|c|c|c|c|c|c|c|}
\hline \multirow[b]{2}{*}{ Age, year, mean (SD) } & \multicolumn{2}{|c|}{$\begin{array}{l}\text { Asphyxia } \\
(\mathrm{n}=2670)\end{array}$} & \multicolumn{2}{|c|}{$\begin{array}{l}\text { Hanging } \\
(n=1999)\end{array}$} & \multicolumn{2}{|c|}{$\begin{array}{l}\text { Fall } \\
(n=1300)\end{array}$} & \multicolumn{2}{|c|}{$\begin{array}{l}\text { Drowning } \\
(n=1062)\end{array}$} & \multicolumn{2}{|c|}{$\begin{array}{l}\text { Traffic injury } \\
(\mathrm{n}=765)\end{array}$} & \multicolumn{2}{|c|}{$\begin{array}{l}\text { Drug } \\
\text { overdose } \\
(n=187)\end{array}$} & \multicolumn{2}{|c|}{$\begin{array}{l}\text { Unclassified } \\
(\mathrm{n}=256)\end{array}$} & \multirow{2}{*}{$\frac{\text { p Value }}{<0.001}$} \\
\hline & 77.9 & $(14.4)$ & 55.6 & $(17.4)$ & 47.4 & $(17.4)$ & 73.1 & $(14.8)$ & 52.6 & $(19.0)$ & 49.9 & $(19.5)$ & 58.1 & (19.3) & \\
\hline Age group, $\mathrm{n}(\%)$ & & & & & & & & & & & & & & & $<0.001$ \\
\hline Adults aged $20-64$ years & 403 & $(15.1)$ & 1136 & $(66.8)$ & 1055 & $(81.2)$ & 210 & $(19.8)$ & 523 & $(68.4)$ & 141 & $(75.4)$ & 158 & $(61.7)$ & \\
\hline Elderly aged $\geq 65$ years & 2267 & (84.9) & 663 & (33.2) & 245 & $(18.8)$ & 852 & $(80.2)$ & 242 & (31.6) & 46 & $(24.6)$ & 98 & (38.3) & \\
\hline Men, n (\%) & 1345 & $(50.4)$ & 1290 & (64.5) & 781 & $(60.1)$ & 530 & (49.9) & 558 & (72.9) & 117 & (62.6) & 168 & $(65.6)$ & $<0.001$ \\
\hline Arrests witnessed by bystanders, $\mathrm{n}(\%)$ & 1801 & (67.5) & 27 & $(1.4)$ & 510 & (39.2) & 56 & $(5.3)$ & 476 & (62.2) & 10 & $(5.3)$ & 72 & (28.1) & $<0.001$ \\
\hline Normal activities of daily living, $n(\%)$ & 1099 & $(41.2)$ & 1769 & (88.5) & 685 & (52.7) & 854 & $(80.4)$ & 517 & (67.6) & 133 & (71.1) & 156 & (60.9) & $<0.001$ \\
\hline First documented rhythm, n (\%) & & & & & & & & & & & & & & & $<0.001$ \\
\hline VF & 56 & $(2.1)$ & 13 & $(0.7)$ & 19 & $(1.5)$ & 12 & $(1.1)$ & 14 & $(1.8)$ & 1 & $(0.5)$ & 4 & $(1.6)$ & \\
\hline PEA & 960 & (36.0) & 198 & (9.9) & 274 & $(21.1)$ & 72 & (6.8) & 259 & (33.9) & 20 & (10.7) & 70 & (27.3) & \\
\hline Asystole & 1589 & (59.5) & 1775 & (88.8) & 985 & (75.8) & 970 & (91.3) & 469 & (61.3) & 160 & (85.6) & 176 & (68.8) & \\
\hline Others & 65 & $(2.4)$ & 13 & $(0.7)$ & 22 & $(1.7)$ & 8 & $(0.8)$ & 23 & $(3.0)$ & 6 & (3.2) & 6 & $(2.3)$ & \\
\hline Location of arrest, $\mathrm{n}(\%)$ & & & & & & & & & & & & & & & $<0.001$ \\
\hline Homes & 1596 & $(59.8)$ & 1667 & (83.4) & 139 & $(10.7)$ & 770 & $(72.5)$ & 2 & $(0.3)$ & 150 & $(80.2)$ & 111 & $(43.4)$ & \\
\hline Public places & 139 & $(5.2)$ & 86 & $(4.3)$ & 553 & (42.5) & 83 & $(7.8)$ & 677 & (88.5) & 14 & (7.5) & 56 & (21.9) & \\
\hline Workplaces & 35 & (1.3) & 94 & $(4.7)$ & 44 & $(3.4)$ & 3 & $(0.3)$ & 7 & $(0.9)$ & 7 & (3.7) & 33 & (12.9) & \\
\hline Healthcare facilities & 835 & (31.3) & 27 & $(1.4)$ & 12 & $(0.9)$ & 14 & (1.3) & 1 & $(0.1)$ & 0 & (0.0) & 15 & (5.9) & \\
\hline Others & 65 & $(2.4)$ & 125 & (6.3) & 552 & $(42.5)$ & 192 & $(18.1)$ & 78 & $(10.2)$ & 16 & (8.6) & 41 & $(16.0)$ & \\
\hline Public-access AED use, $n(\%)$ & 4 & $(0.1)$ & 0 & $(0.0)$ & 0 & $(0.0)$ & 0 & $(0.0)$ & 0 & $(0.0)$ & 0 & $(0.0)$ & 0 & $(0.0)$ & 0.214 \\
\hline Type of bystander CPR, $n$ (\%) & & & & & & & & & & & & & & & $<0.001$ \\
\hline No CPR & 1386 & $(51.9)$ & 1174 & $(58.7)$ & 1191 & $(91.6)$ & 608 & $(57.3)$ & 673 & $(88.0)$ & 154 & $(82.4)$ & 197 & $(77.0)$ & \\
\hline Chest compression-only CPR & 748 & (28.0) & 549 & (27.5) & 93 & $(7.2)$ & 281 & $(26.5)$ & 74 & $(9.7)$ & 23 & (12.3) & 43 & $(16.8)$ & \\
\hline Conventional CPR with rescue breathing & 536 & (20.1) & 276 & $(13.8)$ & 16 & $(1.2)$ & 173 & $(16.3)$ & 18 & $(2.4)$ & 10 & $(5.3)$ & 16 & $(6.2)$ & \\
\hline Intravascular fluid, n (\%) & 540 & (20.2) & 393 & (19.7) & 107 & (8.2) & 281 & $(26.5)$ & 76 & (9.9) & 27 & $(14.4)$ & 34 & (13.3) & $<0.001$ \\
\hline Intubation, n (\%) & 800 & $(30.0)$ & 167 & $(8.4)$ & 41 & $(3.2)$ & 251 & $(23.6)$ & 31 & $(4.1)$ & 33 & $(17.6)$ & 41 & $(16.0)$ & $<0.001$ \\
\hline Epinephrine, n (\%) & 326 & (12.2) & 83 & $(4.2)$ & 41 & (3.2) & 68 & (6.4) & 37 & $(4.8)$ & 6 & (3.2) & 11 & (4.3) & $<0.001$ \\
\hline $\begin{array}{l}\text { Call to contact with a patient by EMS } \\
\text { (EMS response time), min, mean (SD) }\end{array}$ & 7.6 & $(2.9)$ & 7.8 & (3.3) & 7.4 & (3.3) & 9.4 & $(7.6)$ & 7.6 & $(4.2)$ & 14.2 & $(10.7)$ & 9.4 & $(7.3)$ & $<0.001$ \\
\hline $\begin{array}{l}\text { Call to CPR by EMS personnel, min, } \\
\text { mean (SD) }\end{array}$ & 7.9 & $(3.1)$ & 8.6 & (3.9) & 8.2 & (3.8) & 10.0 & $(7.5)$ & 9.3 & $(5.9)$ & 14.4 & $(10.0)$ & 11.0 & $(8.7)$ & $<0.001$ \\
\hline Call to hospital arrival, min, mean (SD) & 28.6 & $(8.6)$ & 28.2 & $(7.9)$ & 27.5 & (8.3) & 29.1 & (9.3) & 27.1 & $(8.8)$ & 32.1 & (11.1) & 29.5 & $(9.4)$ & $<0.001$ \\
\hline
\end{tabular}




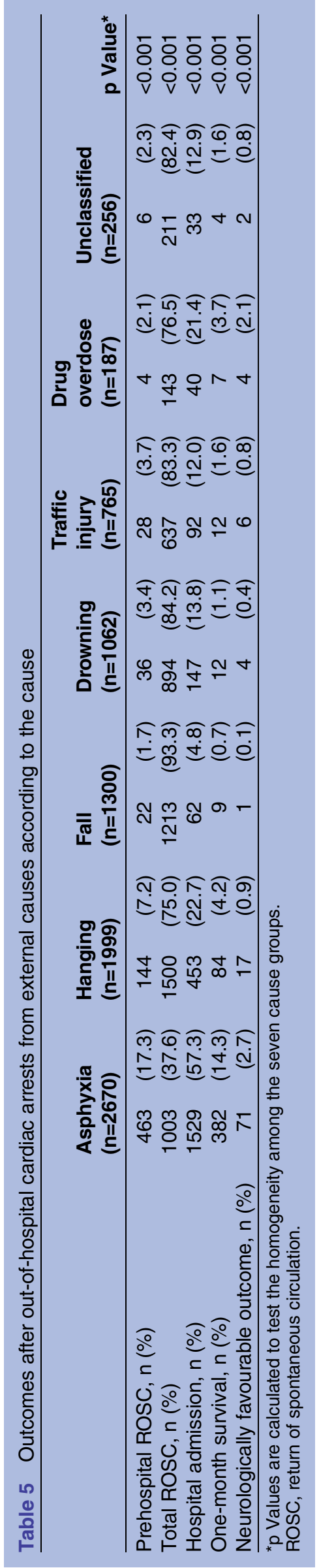

were associated with improving outcome. However, type of bystander CPR, intubation and epinephrine were not associated with better outcome. Compared with asphyxia, the AORs were significantly lower in respiratory diseases $(0.51,95 \%$ CI 0.40 to 0.65$)$, malignant tumours $(0.06$, $95 \%$ CI 0.03 to 0.11$)$, stroke $(0.27,95 \%$ CI 0.20 to 0.38$)$, hanging $(0.56,95 \%$ CI 0.41 to 0.77$)$, fall $(0.03,95 \%$ CI 0.01 to 0.06$)$, drowning $(0.16,95 \%$ CI 0.09 to 0.29$)$ and traffic injury $(0.05,95 \%$ CI 0.03 to 0.10$)$. The proportion of 1-month survival of all OHCAs of non-cardiac origin did not significantly increase (from $4.3 \%(86 / 2023)$ in 2005 to $4.9 \%(105 / 2126)$ in 2011$)$ and the AOR for one-increment of year was 1.01 (95\% CI 0.97 to 1.06 ). The AORs of neurologically favourable outcome after OHCAs of non-cardiac origin were almost similar to those of 1-month survival.

Subgroup analyses after dividing the two groups (internal and external causes) are shown in online supplemental table. As for internal causes, arrests witnessed by bystanders (AOR 2.86, 95\% CI 1.99 to 4.11 ), VF as first documented rhythm (AOR 2.35, 95\% CI 1.30 to 4.24) and public places (AOR 2.01, 95\% CI 1.21 to 3.36) were associated with improving outcome. As for external causes, adults (AOR $1.51,95 \%$ CI 1.17 to 1.96 ), arrests witnessed by bystanders (AOR 5.03, 95\% CI 3.71 to 6.81), good ADL before arrests (AOR 1.34, 95\% CI 1.08 to 1.67), intravenous fluid levels (AOR $1.69,95 \%$ CI 1.27 to 2.25 ) and early EMS response time (AOR for one-increment of minute $0.93,95 \%$ CI 0.90 to 0.96 ) were associated with improving outcome.

\section{DISCUSSION}

The extensive OHCA registry in Osaka showed that 1-month survival after OHCAs of non-cardiac origin was poor and the survival trends did not improve year-by-year. In addition, survival differed by detailed non-cardiac origin. To further improve survival after OHCAs, as much attention should be paid to the epidemiological characteristics of OHCAs of non-cardiac origin as is paid to those of OHCAs of cardiac origin, and this study, describing the actual situation regarding the incidence and outcome of OHCAs of non-cardiac origin, provides valuable information to improve the survival.

Our study observed that the outcomes of OHCAs of non-cardiac origin were poor and stable during the 7 years. In a previous study in Japan, neurologically favourable outcome of bystander-witnessed OHCAs of non-cardiac origin increased from 2005 to 2011, but the absolute survival was very low, ${ }^{7}$ and this result was similar to ours. Improving the outcome of OHCAs of noncardiac origin poses an important problem in resuscitation science because 20-40\% of adult OHCAs are of non-cardiac origin. ${ }^{7-13}$ In addition, survival exceedingly differed by detailed non-cardiac origin, which also suggests the need and importance of an origin-specific strategy for improving the outcomes.

We also showed that the OHCA incidence trends differed by detailed non-cardiac origin. For instance, the 
Table 6 Factors associated with outcomes after out-of-hospital cardiac arrests of non-cardiac origin

\begin{tabular}{|c|c|c|c|c|c|c|c|c|}
\hline & \multicolumn{4}{|c|}{ One-month survival } & \multicolumn{4}{|c|}{ Neurologically favourable outcome } \\
\hline & Crude OR & (95\% Cl) & Adjusted OR & $(95 \% \mathrm{Cl})$ & Crude OR & $(95 \% \mathrm{Cl})$ & Adjusted OR & $(95 \% \mathrm{Cl})$ \\
\hline Adults (vs elderly) & 0.95 & (0.82 to 1.10$)$ & 1.36 & (1.12 to 1.65$)$ & 1.02 & (0.76 to 1.37$)$ & 1.52 & (1.07 to 2.15$)$ \\
\hline Men & 0.75 & $(0.64$ to 0.88$)$ & 0.99 & (0.84 to 1.16$)$ & 1.09 & (0.81 to 1.46$)$ & 0.91 & (0.67 to 1.24$)$ \\
\hline Witnessed by bystanders & 4.41 & (3.74 to 5.19 ) & 4.13 & (3.35 to 5.09$)$ & 4.48 & (3.23 to 6.21 ) & 4.83 & (3.21 to 7.29 ) \\
\hline Good activities of daily living & 0.93 & (0.80 to 1.08$)$ & 1.23 & (1.03 to 1.47$)$ & 1.39 & $(1.02$ to 1.88$)$ & 1.43 & (1.02 to 2.02$)$ \\
\hline VF & 2.74 & (1.96 to 3.82$)$ & 2.04 & (1.42 to 2.92$)$ & 7.72 & (5.05 to 11.79$)$ & 5.40 & (3.40 to 8.59 ) \\
\hline \multicolumn{9}{|l|}{ Type of bystander CPR } \\
\hline No CPR & Reference & & Reference & & Reference & & Reference & \\
\hline Chest compression-only CPR & 0.97 & (0.81 to 1.16$)$ & 0.80 & (0.66 to 0.98$)$ & 0.95 & (0.67 to 1.35$)$ & 0.92 & (0.64 to 1.33$)$ \\
\hline Conventional CPR with rescue breathing & 1.47 & (1.20 to 1.79$)$ & 1.07 & (0.86 to 1.34$)$ & 1.01 & (0.65 to 1.55$)$ & 0.89 & (0.56 to 1.42$)$ \\
\hline \multicolumn{9}{|l|}{ Type of non-cardiac origin } \\
\hline Respiratory diseases & 0.42 & (0.33 to 0.53$)$ & 0.51 & (0.40 to 0.65$)$ & 0.70 & (0.44 to 1.09$)$ & 0.76 & (0.48 to 1.21$)$ \\
\hline Malignant tumours & 0.05 & (0.03 to 0.09$)$ & 0.06 & (0.03 to 0.11$)$ & 0.06 & (0.01 to 0.23 ) & 0.06 & (0.01 to 0.23$)$ \\
\hline Strokes & 0.31 & (0.23 to 0.42$)$ & 0.27 & (0.20 to 0.38$)$ & 0.57 & (0.33 to 0.97 ) & 0.34 & (0.19 to 0.61 ) \\
\hline Asphyxia & Reference & & Reference & & Reference & & Reference & \\
\hline Hanging & 0.26 & (0.21 to 0.34$)$ & 0.56 & (0.41 to 0.77$)$ & 0.31 & (0.18 to 0.53$)$ & 0.55 & (0.28 to 1.07$)$ \\
\hline Fall & 0.04 & (0.02 to 0.08$)$ & 0.03 & (0.01 to 0.06$)$ & 0.03 & (0.004 to 0.20$)$ & 0.01 & (0.002 to 0.11$)$ \\
\hline Drowning & 0.07 & (0.04 to 0.12$)$ & 0.16 & (0.09 to 0.29 ) & 0.14 & (0.05 to 0.38$)$ & 0.31 & (0.11 to 0.90$)$ \\
\hline Traffic injury & 0.10 & (0.05 to 0.17 ) & 0.05 & (0.03 to 0.10$)$ & 0.29 & (0.13 to 0.67 ) & 0.10 & (0.04 to 0.26 ) \\
\hline Drug overdose & 0.23 & (0.11 to 0.50$)$ & 0.58 & (0.26 to 1.29$)$ & 0.80 & (0.29 to 2.21 ) & 1.74 & (0.58 to 5.19$)$ \\
\hline Others & 0.26 & (0.20 to 0.33 ) & 0.29 & (0.22 to 0.38$)$ & 0.67 & (0.45 to 1.00$)$ & 0.60 & (0.39 to 0.92 ) \\
\hline Unclassified & 0.10 & (0.04 to 0.26$)$ & 0.10 & (0.04 to 0.28$)$ & 0.29 & (0.07 to 1.18$)$ & 0.27 & (0.06 to 1.16$)$ \\
\hline \multicolumn{9}{|l|}{ Location of arrest } \\
\hline Homes & Reference & & Reference & & Reference & & Reference & \\
\hline Public places & 0.78 & (0.61 to 0.99$)$ & 1.45 & (1.10 to 1.91$)$ & 1.11 & (0.75 to 1.65$)$ & 1.54 & (0.97 to 2.44$)$ \\
\hline Workplaces & 1.29 & (0.83 to 1.98$)$ & 1.40 & (0.87 to 2.23 ) & 1.26 & (0.55 to 2.89 ) & 0.95 & (0.39 to 2.30$)$ \\
\hline Healthcare facilities & 1.69 & (1.38 to 2.07$)$ & 0.88 & (0.69 to 1.12 ) & 0.72 & (0.42 to 1.24$)$ & 0.47 & (0.26 to 0.85$)$ \\
\hline Others & 0.70 & (0.51 to 0.94$)$ & 1.67 & (1.19 to 2.35$)$ & 0.68 & (0.38 to 1.24$)$ & 1.35 & (0.72 to 2.54$)$ \\
\hline Intravascular fluid & 1.78 & (1.50 to 2.11$)$ & 1.45 & (1.14 to 1.84$)$ & 1.34 & (0.94 to 1.91$)$ & 1.52 & (0.97 to 2.38 ) \\
\hline Intubation & 1.62 & (1.37 to 1.92$)$ & 1.02 & (0.84 to 1.23$)$ & 0.73 & (0.48 to 1.10$)$ & 0.50 & (0.32 to 0.77$)$ \\
\hline Epinephrine & 2.32 & (1.87 to 2.88$)$ & 0.97 & (0.71 to 1.32$)$ & 1.25 & (0.74 to 2.09$)$ & 0.60 & (0.31 to 1.17$)$ \\
\hline EMS response time (for one-increment of minute) & 0.93 & (0.91 to 0.96$)$ & 0.92 & $(0.90$ to 0.95$)$ & 0.91 & (0.86 to 0.96$)$ & 0.90 & (0.84 to 0.95$)$ \\
\hline Year (for one-increment of year) & 1.02 & (0.98 to 1.06$)$ & 1.01 & (0.97 to 1.06$)$ & 1.02 & (0.95 to 1.09$)$ & 1.05 & (0.97 to 1.13$)$ \\
\hline
\end{tabular}


incidence rate of OHCAs due to strokes significantly decreased during the study period. Although the reasons for the decrement were unclear, better blood pressure control and decreasing smoking rate in recent years in Japan might be one of the possible explanations for this phenomenon. ${ }^{20}$ In fact, the number of patients with stroke in Japan has also been decreasing. ${ }^{21}$ On the other hand, the incidence rates of OHCAs from external causes in our region increased and the outcomes after OHCAs from external causes excluding asphyxia were miserable. However, there were regional variations on the incidence and outcome of OHCAs from external causes. $^{22} 23$ For example, external OHCAs due to trauma, drug overdose or hanging in a metropolitan area of Australia were more common and survival rates from traumatic and hanging-associated OHCAs were not always futile, and the countermeasures would, therefore, differ by regions. Most importantly, more efforts should focus on prevention of OHCAs from external causes because many of them are preventable. ${ }^{1-4}$

In a multivariable analysis, intravenous fluid administration was associated with better 1-month survival after OHCAs of non-cardiac origin. In preceding studies, prehospital intravenous fluid for OHCAs including cardiac and non-cardiac origins was not associated with the improved outcome, ${ }^{24}$ whereas intravenous access was associated with a reduction in hospital mortality among non-injured, non-cardiac origin arrest patients. ${ }^{25}$ Thus, the effects of fluid administration on prehospital emergency patients were under debate, and further investigations by other cohorts or randomised controlled trials are needed to confirm these associations.

In this study, a multivariate analysis also underscored that either bystander-initiated chest compression-only CPR or conventional CPR with rescue breathing was not effective for OHCAs of non-cardiac origin. From a nationwide study focused on 43000 bystander-witnessed OHCAs of non-cardiac origin, we demonstrated that conventional CPR with rescue breathing had an incremental benefit for OHCAs of non-cardiac origin, but the impact on overall survival after OHCA was small. ${ }^{8}$ Considering these results, the effectiveness of bystander CPR on OHCAs of non-cardiac origin in our region might be related to the significantly high rates of attempted EMS resuscitation in Japan compared with western countries. ${ }^{22}{ }^{26}$ However, as recommended in the CPR guidelines, ${ }^{1-4}$ bystander CPR plays a key role in the 'chain of survival' and increasing the proportion of performers of bystander CPR for patients with OHCA is important.

Furthermore, factors such as arrests witnessed by bystanders and earlier EMS response time were also independent predictors of better outcome after OHCAs of non-cardiac origin in a multivariate analysis. This would indicate the importance of early EMS activation in the chain of survival ${ }^{1-4}$ and suggests that activating the EMS system quickly leads to improving the outcomes after OHCAs of non-cardiac origin. In addition, verification of the effects on prehospital emergency care as well as in-hospital treatment is essential to improve survival after OHCAs of non-cardiac origin.

The present study has some inherent limitations. First, the category of presumed cardiac or non-cardiac causes is made clinically, as per the Utstein-style international guidelines for cardiac arrest data reporting. ${ }^{14}{ }^{15}$ Second, information on postarrest care is lacking. In-hospital treatment (eg, haemodynamic support, cardiovascular intervention, induced hypothermia) might affect survival after $\mathrm{OHCA}^{27}$ Third, unmeasured confounding factors may have influenced the association between OHCAs of non-cardiac origin and the outcome.

\section{CONCLUSION}

The large OHCA registry in Osaka demonstrated that 1-month survival after OHCAs of non-cardiac origin was poor, the survival trends did not improve year-by-year, and survival differed by detailed non-cardiac origin. Further monitoring and discussion for epidemiology and outcome of OHCAs of non-cardiac origin are warranted to improve survival after OHCA in this group.

\section{Author affiliations}

${ }^{1}$ Division of Environmental Medicine and Population Sciences, Department of Social and Environmental Medicine, Graduate School of Medicine, Osaka University, Suita, Japan

${ }^{2}$ Department of Public Health, Tokyo Women's Medical University, Tokyo, Japan

${ }^{3}$ Department of Traumatology and Acute Critical Medicine, Osaka University Graduate School of Medicine, Suita, Japan

${ }^{4}$ Kyoto University Health Services, Kyoto, Japan

${ }^{5}$ Department of Critical Care Nursing, Graduate School of Medicine and School of Health Sciences, Kyoto University, Kyoto, Japan

${ }^{6}$ Traumatology and Critical Care Medical Center, National Hospital

Organization Osaka National Hospital, Osaka, Japan

${ }^{7}$ Department of Acute Medicine, Kinki University Faculty of Medicine,

Osaka-Sayama, Japan

${ }^{8}$ Senri Critical Care Medical Center, Osaka Saiseikai Senri Hospital, Suita, Japan

Acknowledgements The authors are deeply indebted to all of the EMS personnel and concerned physicians in Osaka Prefecture, and the Osaka Medical Association for their indispensable cooperation and generous support. The authors also thank all members of the Utstein Osaka Project for their contribution in the organisation, coordination and oversight as the steering committee. The authors also thank BEC SERVICE for English language editing in writing the paper.

Contributors All authors participated in the study conception and design, acquisition of data, analysis and interpretation of data, drafting the article and revising it critically for important intellectual content and final approval of the manuscript.

Funding This study was supported by a scientific research grant from the Ministry of Health, Labour, and Welfare of Japan (25112601).

\section{Competing interests None.}

Ethics approval The study was approved by the Institutional Review Board of Osaka University with the assent of the EMS authorities of the local governments in Osaka Prefecture.

Provenance and peer review Not commissioned; externally peer reviewed.

Data sharing statement TK had full access to all of the data in the study and takes responsibility for the integrity of the data and the accuracy of the data analysis. 
Open Access This is an Open Access article distributed in accordance with the Creative Commons Attribution Non Commercial (CC BY-NC 4.0) license, which permits others to distribute, remix, adapt, build upon this work noncommercially, and license their derivative works on different terms, provided the original work is properly cited and the use is non-commercial. See: http:// creativecommons.org/licenses/by-nc/4.0/

\section{REFERENCES}

1. International Liaison Committee On Resuscitation. 2010 International consensus on cardiopulmonary resuscitation and emergency cardiovascular care science with treatment recommendations. Circulation 2010;122:S250-605.

2. American Heart Association Emergency Cardiovascular Care Committee. 2010 American Heart Association guidelines for cardiopulmonary resuscitation and emergency cardiovascular care. Circulation 2010;122:S639-946.

3. European Resuscitation Council Guidelines Writing Group. European Resuscitation Council Guidelines for Resuscitation 2010. Resuscitation 2010;81:1219-451.

4. Japan Resuscitation Council. 2010 Japanese guidelines for emergency care and cardiopulmonary resuscitation. 1st edn. Tokyo: Health Shuppansha, 2011 (in Japanese).

5. Iwami T, Nichol G, Hiraide A, et al. Continuous improvements of chain of survival increased survival after out-of-hospital cardiac arrests: a large-scale population-based study. Circulation 2009;119:728-34

6. Rea TD, Helbock M, Perry S, et al. Increasing use of cardiopulmonary resuscitation during out-of-hospital ventricular fibrillation arrest: survival implications of guideline changes. Circulation 2006;114:2760-5.

7. Kitamura T, Iwami T, Kawamura T, et al. Nationwide improvements in survival from out-of-hospital cardiac arrests in Japan. Circulation 2012;126:2834-43.

8. Kitamura T, Iwami T, Kawamura T, et al. Bystander-initiated rescue breathing for out-of-hospital cardiac arrests of non-cardiac origin. Circulation 2010;122:293-9.

9. Kuisma M, Alaspää A. Out-of-hospital cardiac arrests of non-cardiac origin. Epidemiology and outcome. Eur Heart J 1997;18:1122-8.

10. Engdahl J, Bång A, Karlson BW, et al. Characteristics and outcome among patients suffering from out of hospital cardiac arrest of non-cardiac aetiology. Resuscitation 2003;57:33-41.

11. Hess EP, Campbell RL, White RD. Epidemiology, trends, and outcome of out-of-hospital cardiac arrest of non-cardiac origin Resuscitation 2007;72:200-7.

12. Iwami T, Hiraide A, Nakanishi N, et al. Age and sex analyses of out-of-hospital cardiac arrest in Osaka, Japan. Resuscitation 2003;57:145-52.

13. Engdahl J, Holmberg M, Karlson BW, et al. The epidemiology of out-of-hospital 'sudden' cardiac arrest. Resuscitation 2002;52:235-45.

14. Cummins RO, Chamberlain DA, Abramson NS, et al. Recommended guideline for uniform reporting of data from out-of-hospital cardiac arrest: the Utstein style: a statement for health professionals from a task force of the American Heart Association, the European Resuscitation Council, the Heart and Stroke Foundation of Canada, and the Australian Resuscitation Council. Circulation 1991:84:960-75.

15. Jacobs I, Nadkarni V, Bahr J, et al. Cardiac arrest and cardiopulmonary resuscitation outcome reports: update and simplification of the Utstein templates for resuscitation registries: a statement for healthcare professionals from a task force of the International Liaison Committee on Resuscitation (American Heart Association, European Resuscitation Council, Australian Resuscitation Council, New Zealand Resuscitation Council, Heart and Stroke Foundation of Canada, Inter American Heart Foundation, Resuscitation Councils of Southern Africa). Circulation 2004;110:3385-97.

16. Nitta M, Iwami T, Kitamura T, et al. Age-specific differences in outcomes after out-of-hospital cardiac arrests. Pediatrics 2011;128 e812-20.

17. Atkins DL, Everson-Stewart S, Sears GK, et al. Epidemiology and outcomes from out-of-hospital cardiac arrest in children: the Resuscitation Outcomes Consortium Epistry-Cardiac Arrest. Circulation 2009:119:1484-91.

18. 2010 Population Census of Japan. http://www.stat.go.jp/data/ kokusei/2010/index.htm?utm source=twitterfeed\&utm medium=twitter (accessed 5 Aug 2014) (in Japanese).

19. Ministry of Health, Labour and Welfare. Vital Statistics of Japan 2005. Tokyo: Health and Welfare Statistics Association, 2007.

20. Hata J, Ninomiya T, Hirakawa Y, et al. Secular trends in cardiovascular disease and its risk factors in Japanese: half-century data from the Hisayama Study (1961-2009). Circulation 2013;128:1198-205.

21. 2011 Overview of Patient Survey. http://www.mhlw.go.jp/toukei/ saikin/hw/kanja/11/ (accessed 5 Aug 2014) (in Japanese).

22. Deasy C, Bray J, Smith K, et al. Traumatic out-of-hospital cardiac arrests in Melbourne, Australia. Resuscitation 2012;83:465-70.

23. Deasy C, Bray J, Smith $\mathrm{K}$, et al. Hanging-associated out-of-hospital cardiac arrests in Melbourne, Australia. Emerg Med $J$ 2013:30:38-42.

24. Hagihara A, Hasegawa M, Abe T, et al. Prehospital lactated ringer's solution treatment and survival in out-of-hospital cardiac arrest: a prospective cohort analysis. PLoS Med 2013;10:e1001394.

25. Seymour CW, Cooke CR, Hebert PL, et al. Intravenous access during out-of-hospital emergency care of noninjured patients: a population-based outcome study. Ann Emerg Med 2012;59:296-303.

26. Nichol G, Thomas E, Callaway $\mathrm{CW}$, et al. Regional variation in out-of-hospital cardiac arrest incidence and outcome. JAMA 2008;300:1423-31.

27. Neumar RW, Nolan JP, Adrie C, et al. Post-cardiac arrest syndrome: epidemiology, pathophysiology, treatment, and prognostication. A Scientific Statement from the International Liaison Committee on Resuscitation; the American Heart Association Emergency Cardiovascular Care Committee; the Council on Cardiovascular Surgery and Anesthesia; the Council on Cardiopulmonary, Perioperative, and Critical Care; the Council on Clinical Cardiology; the Council on Stroke. Circulation 2008;118:2452-8. 